\title{
Research
}

\section{Customer Information Systems}

\section{Approaching a new field in information systems from a new perspective}

\author{
Ko de Ruyter and Joost Zuurbier . \\ University of Twente, Enschede, The Netherlands
}

Recent years have witnessed an increasing awareness and need for information systems that can fulfil a role on the boundary between organisations and their environments. However, these so-called Customer Information Systems (CIS) have been developed using a traditional design approach with an emphasis on information systems that ignores the role of social systems in business decision-making. Consequently, a number of well-known problems concerning the use of information technology have also risen in the CIS area. Therefore, we propose a new design approach to CIS inat addresses responsibilities and norms in business decision-making and focuses on the interplay between information systems design and organisational design. We propose extensions of current design issues that - if successful - could be of interest for researchers as well as practitioners.

Keywords: Systems design; Group decision-making; Customer Information Systems; Customer service; Social systems; NORMA.

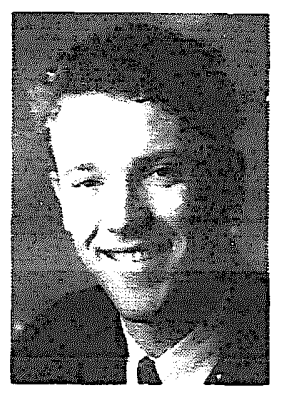

Ko de Ruyter is assistant professor at the University of Twente, School of Management Studies, Enschede. The Netherlands. He was a visiting professor in Consumer Economics at Purdue University, Indiana, United States. Ko de Ruyter has written various articles on the relationship between customer service and information technology. He has also done Consumer Affairs consulting for various companies, both in the United States and in Europe.

Correspondence to: $\mathrm{K}$. de Ruyter, University of Twente, P.O.Box 217, 7500 AE Enschede, The Netherlands. Tel: +31 53893912 . Fax: + 3153339985 .

\section{Introduction}

The recent growth of the service sector in the international economy and the increase in global competition where price and quality differences are becoming minimal is placing greater emphasis on the concept of customer service as a strategic factor [2,14]. Increasingly, customer service is seen as a primary mechanism for maintaining market share and gaining a competitive edge $[6,7,10]$. According to the Total Quality Management tradition, a company should no longer depend on internal standards. Instead, the customer's perception of quality is what should be used to assess organizational performance [5].

Public policy makers arc responding to this trend. For instance, European Community legislation in the fields of product safety and product liability prescribes implementing systematic procedures for assessing and investigating customer complaints [12]. The response from private business has been a wide-spread introduction of Customer Service departments charged with providing intelligence on customer matters. These organizational functions collect customer data by means of satisfaction surveys, focus groups, and

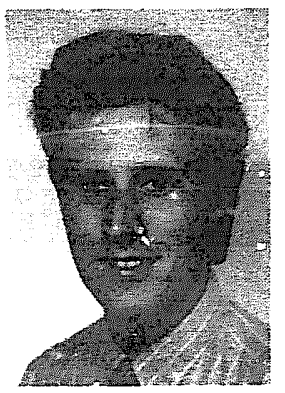

Joost Zuurbier is a PhD candidate at the University of Twente, School of Management Studies, Enschede, The Netherlands. His research concerns the development of decision support systems. He is a lecturer on this subject at the University of Twente. Joost Zuurbier is also engaged at the 'Medisch Spectrum Twente', a large non-teaching hospital, department of Information Affairs, for the development of financial decision support. He authored several articles in this field. 
toll-free telephone lines that allow the company to listen to the requests and concerns of its customers. Gradually, it is becoming clear that there is a need for systems that can process this data into actionable management information.

Unfortunately, however, organizational information systems design by-and-large has only marginally responded to these needs. Technological developments in the design of Decision Support Systems (DSS) and Executive Information Systems (EIS) have extended the possibilities of information processing, but questions have been raised regarding the effectiveness of such progress $[13,15]$. Moreover, the focus has been exclusively on internal operations, providing reports on production and sales volumes, finance, quality control, etc. These systems hardly tell company management anything about their customers. Although many organizations make use of a customer database containing straightforward facts, such as account number, addresses, purchasing and payment records, etc., they do not contain any information on customer expectations and perceptions and how the organization's performance relates to this [1]. As early as 1983, research revialed that "many companies do not take advantage of information available...thereby spending almost all of the necessary resources but gaining only some of the benefits" [3]. Consequently, there is a need for designing systems that adopt a more "boundary spanning" role, providing the organization interaction with its customers. Such Customer Information Systems (CIS) should assist management in planning, analysis, decision-making and control in the customer service strategy $[11,14]$.

Effective design of CIS requires a different theoretical perspective, relating information systems to social systems [19], instead of focusing, as is traditionally done, on technological aspects.

\section{Practical problems}

In our study of a large moderately-priced U.S. department store chain, the manager responsible for the CIS and corporate management were interviewed. The chain specializes in nationally branded and high quality private-label, casual apparel. The company has 235 stores in 15 states, most of which are on the West Coast of the U.S., employing 46,000 people. The CIS within the company's Information Centre has isen operational for three years. In the course of these three years company management has gradually lost interest in the customer information provided by the Information Centre. Initially, all store managers, 22 district managers and 110 corporate managers received this information. Presently, the Information Centre has only three internal customers left: the quality of its information is considered very poor. According to respondents, this was due to three attributes of the information.

In the first place, the content of the information was not in accordance with management's needs for decision-making. It was argued that the information did not give a representative indication of performance, as it was not related to company standards. For example, a reported increase $(29 \%)$ in the number of customer complaints about the company's cosmetic product line during the third quarter was not presented with resnect to the number of sales, particular districts, or specific products and/or problems. It was argued that this did not provide enough information for decision-making. Furthermore, the data processed by the CIS within the Information Centre was not integrated with customer satisfaction data as acquired by other departments, such as Market Research and Quality Control. Thus, trends in complaints or product returns could not be related to the company's customer satisfaction index. Finally, the information could not be related to previous periods e.g., for correction of seasonal influences. In short, the content of the information provided no basis for action.

The second information attribute concerned user-friendliness of the information format. As a rule, the results of both quantitative and qualitative analysis of customer data were presented in Inng "laundry lists" pertaining to nearly every department within the company. These were very time-consuming to read. More often than not, therefore, Information Centre reporting was ignored.

The third attribute needing improvement was timeliness. On the one hand, reporting at quarterly intervals did not provide timely enough information. On the other hand, access to information is the form of ad hoc reporting related to 
particular problems or questions was too limited or time-consuming to be useful.

In addition, other factors were mentioned. Feedback from customers was not universally considered a challenge within the company; some district and store managers consider it a threat. Moreover, some were motivated more by financial objectives than a customer satisfaction index. Also it was not clear which functional manager was to be held responsible for customer dissatisfaction.

\section{The principle of business semantics}

The concept of "business semantics" departs from the perspective of subjective reality within an organizational context. People have conflicts of view and reformulate their view reality in negotiations with other organizational members. Business semantics, therefore, refers to the consensus in an organization about the boundaries of objects, norms, procedures, responsibilities, meanings, interpretations, etc. Such consensus and subsequent decision-making rests on subjective interpretations.

To illustrate the concept for a specific CIS environment, we use a complaint data set from the Customer Service Centre of a large multi-national photo equipment manufacturer. In a customer satisfaction monitoring committee meeting, Figure 1 was presented by the Customer Service manager. On the basis of this, obviously rather crude frequency distribution table, the corporate management might conclude that customer satisfaction is highest in District II and lowest in

\section{Frequency distribution complaints} Consumer segment (week 43)

\begin{tabular}{|c|c|c|}
\hline DISTRICTS & NO. COMPLAINTS & RELATIVE \% \\
\hline DISTRICTI & 120 & 9.72 \\
\hline DISTRICT ॥ & 270 & $21.88^{\circ}$ \\
\hline DISTRICT III & 200 & 16.20 \\
\hline DISTRICT IV & 87 & 7.05 \\
\hline DISTRICT V & 120 & 9.72 \\
\hline DISTRICT VI & 42 & 3.40 \\
\hline DISTRICT VII & 200 & 16.20 \\
\hline DISTRICT VIII & 45 & 3.64 \\
\hline \multirow[t]{2}{*}{ DISTRICT IX } & 150 & 12.15 \\
\hline & gasumens & Ansugusas \\
\hline TOTAL & 1234 & 100.00 \\
\hline
\end{tabular}

Fig. 1. Frequency distribution complaints.

\section{Normalized distribution complaints}

Consumer segment (week 43)

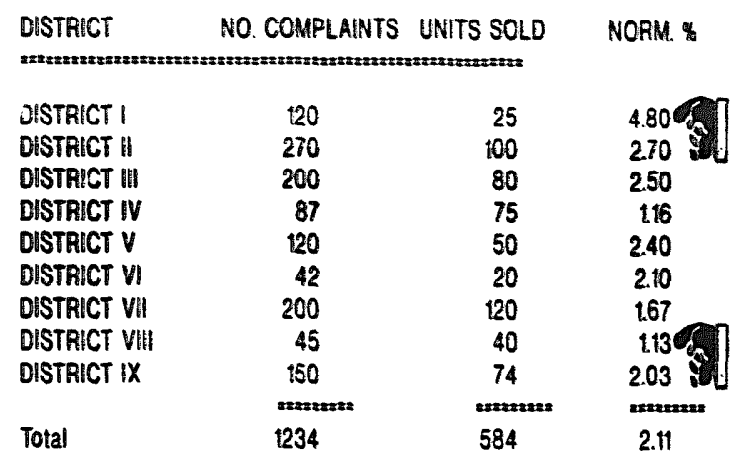

Fig. 2. Normalized distribution complaints.

District VI. At the request of the District manager of the latter, who was understandably unhappy with the presentation of the figures, complaint frequencies were related to the number of units sold (Figure 2). Presenting the same data set in a different (normalized) manner, using an arbitrary norm, also yields an entirely different meaning to the distribution of complaint frequencies in the districts. This may well lead to different management decision-making at the corporate level. According to the manager of district $\mathbf{I}$, however, there might be a hidden meaning to the relative high incidence of complaints in his district.

By presenting the data with relation to product model (Figure 3), a different problem surfaces. For example, model $\mathrm{E}$, which is responsible for a

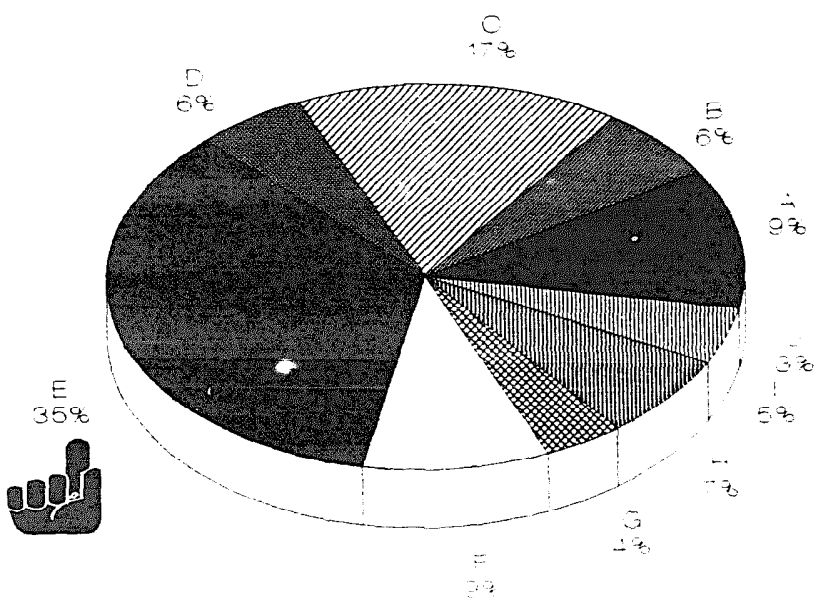

Fig. 3. Complaints by product model. 
iarge percentage of consumer complaints, is a product which belongs to the professional segment in the eyes of its manager and should, therefore, be excluded from analysis of the consumer segment. This example shows how the presentation sometimes becomes the basis for decision making at the higher levels in the organization [17]. The existence of business semantics implies sorting out conflicts of view and interest, making explicit norms and solving problems of meaning.

Besides exemplification, we should like to clarify further the concept of business semantics by making two observations.

\section{The meaning of meaning}

The word meaning has different interpretations but in organizational decision-making, meaning does not belong to words or symbols but to their use in a social context, particularly in situations of distributed decision-making $[8,9]$. Such situations occur more and more when Custome jervice is recognized as a strategic factor, sinc this requires a focus on the customer that goes beyond traditional functional boundaries (e.g., forming a project team with different functional backgrounds). Following a semiotic framework to organizational information processing, meaning can be understood as the relation between sign and behaviour, with information being the properties or attributes of signs. CIS data which is not related to other customer data, which does not fall within a particular decision-making time-frame, which does not meet specific standards of user-friendliness and consequently does not result in behaviour, basically has no meaning, according to company management. In other

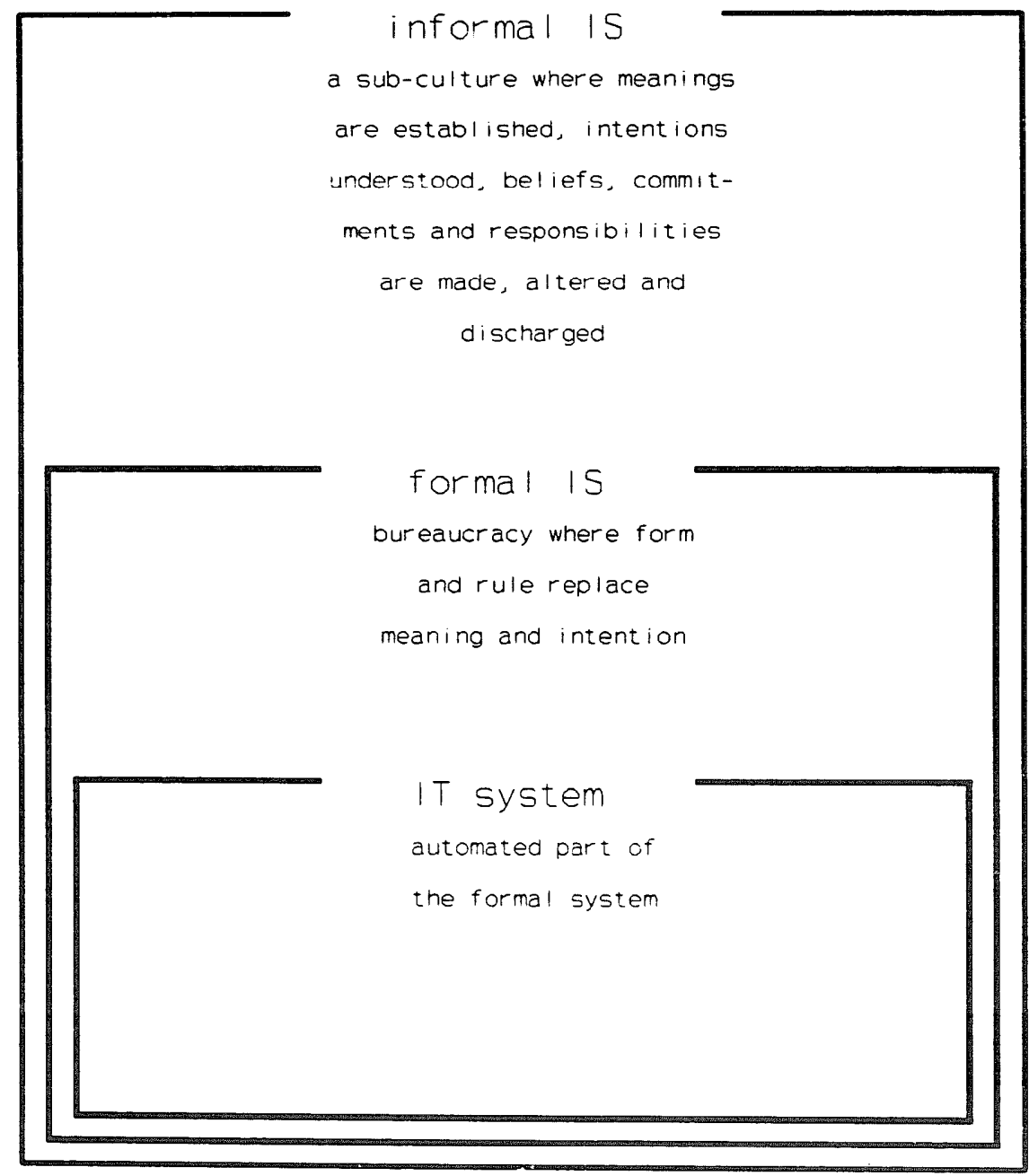

Fig. 4. The real information system. 
words, it is not actionable. Therefore, our approach should relate the data to organizational groups (company management) who understand and need it [17].

\section{The informality of formal decision-making}

Business decision making is information processing in an organization. Problems related to decision-making due to conflicts of view can only be solved by incorporating the informal, social system. For particular areas this system has been formalized, presuming an objective reality. This is "bureaucracy" (see Figure 4). Aspects of the rules for formal decision-making can be automated, becoming information systems. Establishment of a department for providing Customer Service information, for instance, is a form of bureaucracy. It is an institutionalization of the company's customer orientation. Because the problems of meaning have been sorted out before the bureaucracy was created, the people in bureaucracies often act in a mechanical way. They have no understanding of the words used on all kinds of forms, and they seemingly do not need to. For instance, if all customer problems relating to warranty cases are sent to the Financial department, they may receive long lists of data from which they are often unable to filter information. The shift in competition and the dynamics of improvement could require involvement of the Customer Service and Quality Control departments instead.

Formal organizational decision-making is largely dependent upon an informal system. It is on this level that people have to negotiate to reach a consensus, the starting point for formal decision-making. Without this consensus, solid bureaucracy and information technology (IT) systems cannot be built. And this may lead to variable formal decision-making. When several functional managers in an organization learn from CIS data from the Customer Relations department that a particular problem is causing customer dissatisfaction, they may undertake different actions and show different behaviour. One may merely correct existing problems by, for instance, replacing defictive products for the most loyal customers. Another may take measures that prevent the same problem from occurring in future by adjusting the production process, redesigning the product, or applying stricter quality control measures. Finally, a third may choose to simply ignore the problem, arguing that com- plaints have been received from a small proportion of the customer population. Here we see the informality of decision-making in action.

\section{Towards a solution}

What do these observations tell us? Before we are able to automate business processes we must have consensus on the meaning. This consensus has to be reached on the informal level. Tools which can help us reaching this consensus become even more important when we realize that only a small fraction of all business decisions are handled by a formal system. Furthermore, shifts in meaning in the informal organizational system are important, as they may affect the company's competitive edge. We illustrate this in a second case study.

It a ncerns a southern-California-based, mediur sized manufacturer of skin- and hair care products. Its centralized production facility employed approximately 800 people. Since the introduction of the CIS, every member of corporate management had been receiving quarterly reports. Analysis of CIS data showed that the packaging of a new type of skin care product was causing considerable customer dissatisfaction. On the basis of this information, it was decided to form a project to find some possible solutions; the problem area was diverse (size, weight, breakage etc.) and a final solution to the problem depended on a number of internal constraints. According to Marketing, the packaging had to be transparent, Quality Control was primarily concerned with its solidity, $R$ and $D$ with the robustness of the product's microbiological system and Legal with product liability and product safety matters. Furthermore, costs restraints and availability of materials by external suppliers had to be considered. In the decision-making process, the CIS (a formal system) has a limited role; it provides the signals that enable project team members to identify a problem. The choice of one particular solution (a form of consensus) depends much more on the informal system. After an alternative packaging was introduced, CIS output was once again used to monitor the effectiveness of the solution. Thus the role of the IT system remains limited. Moreover, there is an interplay between information system design (e.g., 
what inputs are used) and organizational design (e.g., the formation of an interdisciplinary project team).

The conceptual framework for the project team case can be related to Figure 4 . In traditional approaches of information systems design, the connecti as between the IT system and the formal system are emphasized. Nonetheless, from the case material it appears that the connections between the formal and the informal system also play an important role. Especially in situations of distributed or group decision-making [9].

\section{A social approach to CIS design}

In our definition the meaning of a sign, as represented by information, is the expectation someone has about the behaviour or action some person is going to show on basis of this information. Therefore, to reach a consensus as meant above, we have to understand:

(1) who is in charge of what;

(2) according to what information or conditions should he or she act?

The "who" are the "agents" in our social system. The "what" is the "behaviour" desired by the system. The "conditions" in which this behaviour is desired are the "norms." These ultimately influence the decision structure (usually rendered as an information flow diagram). It is shown in Figure 5. In the remainder of this article we shall elaborate on the above questions.

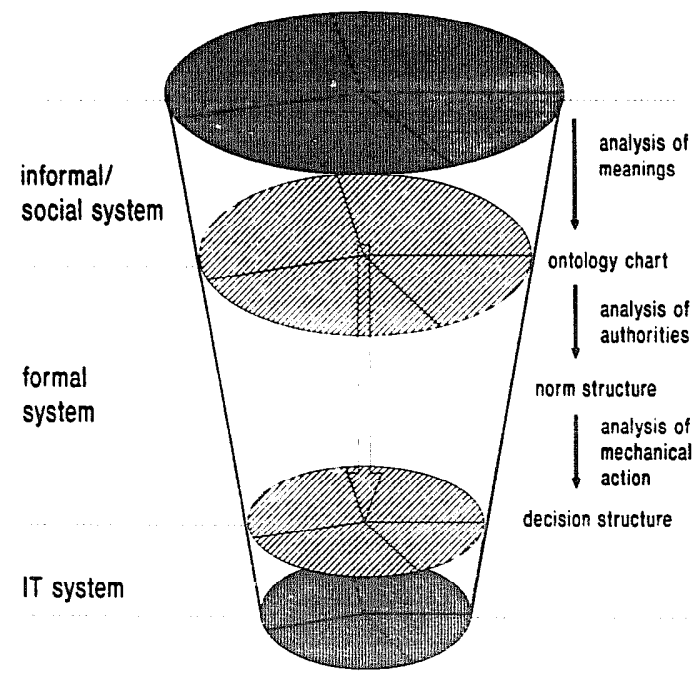

Fig. 5. A CIS design approach.

\section{Semantic analysis}

Our method of specifying relevant agents and their behaviour, is called NORMA. In it, all phenomena in any environment are seen as behavioral extensions of the agent [4]. For instance, the agent "customer" can show "complaining behaviour". However, a company too can be considered an agent. According to the law, for instance, a company is a legal person who can be held responsible for its actions (behaviour). In NORMA, we refer to the ways an agent can behave as "affordances." In our case, "complaining behaviour" is an affordance of a customer (the agent). Basically, this is all NORMA offers, agents and affordances [16].

In NORMA, we describe the ontological dependence between agents and affordances. For example, complaining behaviour cannot exist without a complainant. Therefore, complaining behaviour is ontological dependent on a complainant. Using formal language, ontological dependency can be defined as follows: given two objects $\mathrm{x}$ and $\mathrm{y}$; if $\mathrm{y}$ can exist only during or within the existence of $x$, then the dependency relationship between $x$ and $y$ is defined as ontological dependency: $\mathbf{y}$ ontologically depends on $\mathbf{x}$.

On the jasis of ontological dependence, semantic analysis is performed in four consecutive steps. We illustrate this by revisiting the previous "project team case". Suppose a project team has been formed to solve a problem that was causing customer dissatisfaction.

1. In discussing this problem, the members of the social group (i.e. the project team) construct a list of semantic units; these are the possible agents and affordances. Only terms used by the user group can be candidate affordances. For the project team case, the relevant semantic units are:

-customer;
-Marketing department;
-Customer Service
Manager;
-manager;
-Customer Service report
-replacement;
-project team;
-response;
-ownership;
-management;
-Quality Control
department.

-company;

-Legal department;

-Customer Service department;

-complaint;

-refund;

-response letter;

$-\mathrm{R}$ and $\mathrm{D}$ department;

-produci;

-complainant;

-Board of Directors; 
Ideally, the analysis is done by the group with a specialist "facilitator", for instance, a CIS specialist.

2. Secondly, we classify the semantic units. This involves identifying agents and affordances and grouping them. In our case, "person" is an agent, affording the behaviour "management." A person can also afford the behaviour "ownership" if he or she buys a product. We shall in that case call the agent a "customer." In our chart/analysis, a customer can issue a complaint. However, many companies also register complaints with respect to other elements of the marketing mix, such as personnel behaviour, availability of the product, and even parking space. For these companies, a customer does not necessarily have to be a person who actually bought the product! Working on an ontology chart will thus lead to discussions which will bring about the social reality of the problem owners and will make explicit the often implicit organizational procedures. The complaint is registered, but response to the complainant falls under the responsibility of the Customer Service manager, who has the authority to choose a response: an affordance. On the basis of a number of complaints, a Customer Service report can be made. This is also the responsibility of the Customer Service manager. The report can trigger the formation of a project team to solve a serious problem, but only by the Board of Directors. So, the company behaviour is again an affordance. A project team may consist of participants

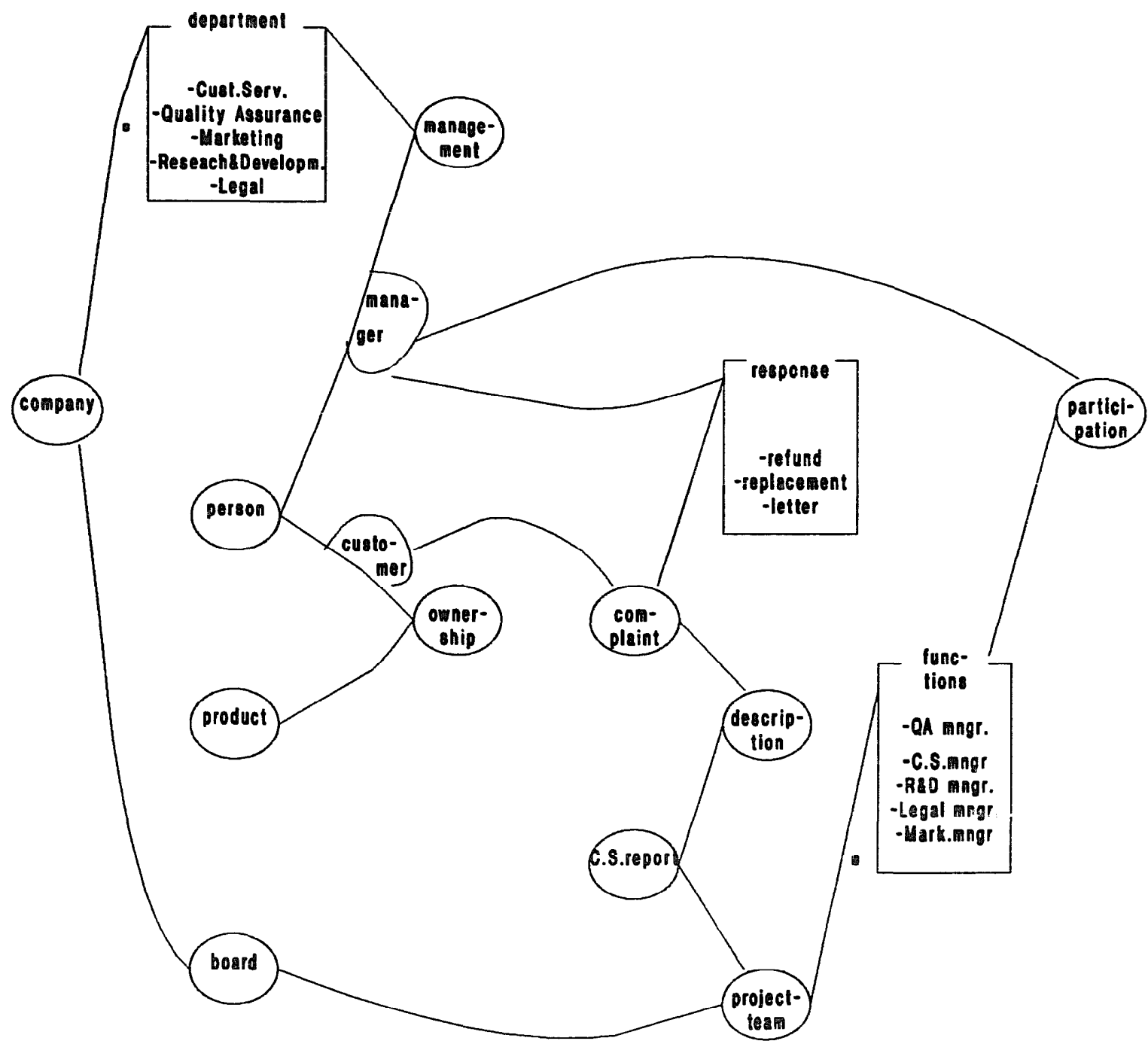

Fig. 6. Customer service ontology chart or business map. 
from various functional backgrounds, e $A d^{r}$ keting, Legal, Quality Control, $\mathbf{R}$ and in! Customer Service.

These are importani business semistio. we express in our analysis: it forces us to tuan cxplicit the often implicit organizational prosedures:

- who is a complainant;

- what is a complaint;

- when can a project team be formed;

- which functional managers should participate in the project team?

The second question may have important inplications: This was under discussion during the design phase for an international manufacturer of elevators. Should complaints be defined narrowly in terms of written customer reaction, or should the concept be defined broadly in terms of all malfunctions. The difference may be between 1,000 and 30,000 a year.

3. A first set of ontology charts or business maps can now be created. In each chart we specify the dependencies between the semantic units. An example for the project team case is given in Figure 6. The chart is read from left to right: the antecedents are always on the left of the dependent.

4. The model then can be discussed with the members of the social group, i.e. the project team. They will give their comments and make adjustments. This will lead to revised charts. The final version chart represents the important semantics of the business domain under analysis. Ultimately, it is formed on the basis of consensus among the members of the project team. Thus, NORMA takes the standpoint of a subjective rather than an objectice reality.

\section{Norm analysis}

In addition to the responsibilities specified in the ontology chart we can perform a norm analysis. The norms govern the organizational decision structure and relate to affordances in the ontology chart. To us, action norms are the most important [18] and can be divided into:

- standing orders: these change the physical world;

- status norms: they change the social world;

- powers of intervention: which invoke or inhibit the use of existing norms;
- powers of legislation: that cinange the norm structure itself.

Norms specify authority: either to behave in a certain way (standing orders/ status norms) or for norms (powers of intervention/legislation). Norms can be formally written in a langudge such as LEGOL, but this it not further addressed here. Some examples of norms are:

1. Standing orders state the conditions under which an action should take place.

"A table of chstomer complaints related to products sold in each district should be produced before the 15th of each month"

2. Status norms create a social structure to perform actions. This will simplify or replace the formal system.

"Customer Service representatives have the authority to award refunds up to a maximum of $\$$ 750 "

3. Powers of intervention create power that may be exercised by an agent. This may concern standing orders as well as status norms.

"The Customer Service manager can decide to overrule a representative's decision to refund"

4. Powers of legislation change the norm structure itself.

"According to the recently accepted E.C. Directive on Product Safety, individual companies have to use product-lots identification marks, sample testing of marketed products and systematic procedures for assessing and investigating complaints by users of the products"

Thus, norm analysis "enables" us to formalize the informal system to a certain level, relating the business semantics specified in the ontology chart to formal decision-making. The status norm applies to the majority of all refunds. However, the importance of the informal system cannot be over-emphasized. For instance, when a customer does not want to settle for the maximum refund of $\$ 750$, a consensus-based decision on how to act still has to be reached among the Customer Service, Financial, and Legal managgers, or by courts of law if legal action is the resulr.

\section{Concluding remarks}

Analysis of case material has lead to the identification of an often neglected problem area in Customer Information Systems design. We have 
attempted to conceptualize this problem field into two observations: problems of meaning and the role of the informal system in business decisionmaking. We have argued that these problems can be addressed by connecting the formal to the informal system in organizations. To this end, we introduced semantic and norm analysis. Semantic analysis leads to a representation of the responsibility structure, thereby addressing problems of meaning, in the form of an ontology chart. Norm analysis leads to a further specification of authorities, thus attempting to formalize a part of the informal system for the purpose of business decision-making. We have tried to demonstrate the applicability of our approach in a second case description concerning a project team and practical examples. We feel that this approach could be useful in other areas of systems design as well.

\section{Acknowledgements}

The authors would like to express their sincere appreciations to Prof. R.K. Stamper M.A., for his comments on this paper. His unlimited enthusiasm forms an invaluable source of inspiration. We would also like to thank the anonymous referees of Information and Management for their constructive critical comments.

\section{References}

[1] Anton, J., T.R. Bennett and R. Widdows, Customer Response and Information Systems (1991). Whitehaven: The Waterfront Press.

[2] Bowen, D.E., C. Siehl and B. Schneider, "A framework for analyzing customer service orientations in manufacturing", Academy of Management Review, 14 (1989) 7595.

[3] Dubin, E.Z. and L.F. Titlebaum, "Data analysis: the return on investment for consumer information management", Mó̀ius (1984) 13-15. Alexandria: SOCAP.
[4] Gibson, J.J., The Ecological Approach to Vistal Perception (1986). London: Lawrence Erbaum.

[5] Hakes, C. (ed.). Total Quality Management (1991). London: Chapman Hall.

[6] Johnson, M.D. and C. Fornell, "A framework for comparing customer satisfaction across individuals and product categories". Journal of Economic Psychology, 12 (1991) 267-286.

[7] Lovelock, C.H., Services Marketing (1991). Englewood Cliffs: Prentice Hall.

[8] Methlie, L.B. and Sprague, R.H. (eds.), Knowledge Representation for Decision Support Systems, Proceedings of the IFIP WG 8.3 working conference (1985). Amsterdam: North Holland.

[9] Nour, M.A. and D. Yen, "Group decision support systems, towards a conceptual foundation", Information and Management, 23 (1992) 55-64.

[10] Reichfeld, F.F. and W.E. Sasser, "Zero defections: Quality comes to services", Harvard Business Review (1990) 105-111.

[11] Ruyter, J.C. de and R. Widdows, CIS: a new frontier for MIS, Prometheus, The Journal of Issues in Technological Change, Innovation, Information Economics, Communication and Science Policy, 10 (1992) 5-16.

[12] Ruyter, J.C. de and A. Brack, "Keeping up with European legal developments on product safety and liability: the role of customer complaint management as a defensive marketing tool", European Journal for Research in Marketing (1993), in press.

[13] Schaik, F.D.J. van, Effectiveness of Decision Support Systems (1988). Delft: University Press.

[14] Selig, F., "Managing information technology in the nineties", Information and Management, 21 (1991) 251255.

[15] Sharda, R., Barr, S.H. and McDonnell, J.C., "Decision support system effectiveness: A review and an empirical test", Management Science, 34 (1988) 2, 139-159.

[16] Stamper, R.K., et al., "From database to normbase", International Journal of Information Management, 11 (1991) 1, 67-84.

[17] Stamper, R.K., "The processing of business semantics", in: Meersman, R. (ed.), Knowledge and Data, Edited proceedings of the IFIP TC2 WG 2.6 working conference (1988). Amsterdam: North-Holland.

[18] Stamper, R.K., "LEGOL: Modelling legal rules by computer", in: Niblett, B. (ed.), Computer Science and Law (1980). Cambridge: University Press.

[19] Waema, T.M. and G. Walsham, "Information systems strategy formulation", Information and Management, 18 (1990) 29-39. 